\title{
Corrigendum to "Mesenchymal Stem Cells Attenuate Radiation-Induced Brain Injury by Inhibiting Microglia Pyroptosis"
}

\author{
Huan Liao, ${ }^{1,2}$ Hongxuan Wang, ${ }^{1,2}$ Xiaoming Rong, ${ }^{1,2}$ Enqin Li, \\ Ren-He $\mathrm{Xu},{ }^{3}$ and Ying Peng $\mathbb{D}^{1,2}$ \\ ${ }^{1}$ Department of Neurology, Sun Yat-Sen Memorial Hospital, Sun Yat-Sen University, Guangzhou, China \\ ${ }^{2}$ Guangdong Provincial Key Laboratory of Malignant Tumor Epigenetics and Gene Regulation, Sun Yat-Sen Memorial Hospital, \\ Sun Yat-Sen University, Guangzhou, China \\ ${ }^{3}$ Faculty of Health Sciences, University of Macau, Taipa, Macau, China
}

Correspondence should be addressed to Ying Peng; docpengy123@163.com

Received 6 June 2018; Accepted 27 June 2018; Published 18 July 2018

Copyright (C) 2018 Huan Liao et al. This is an open access article distributed under the Creative Commons Attribution License, which permits unrestricted use, distribution, and reproduction in any medium, provided the original work is properly cited.

In the article titled "Mesenchymal Stem Cells Attenuate Radiation-Induced Brain Injury by Inhibiting Microglia Pyroptosis" [1], Dr. Enqin Li and Dr. Ren-He Xu were missing from the authors' list. They contributed to establishing the mesenchymal stem cell line and maintaining the quality of the cell cultures. They worked on the stem cells for the subsequent experiment. The corrected authors' list is shown above and corrected in place.

Additionally, the sentence "Thanks are due to Professor Ren-He Xu from University of Macau for his gifts of human trophoblast-derived mesenchymal stem cells" should be removed from the Acknowledgments. This has been corrected in place.

\section{References}

[1] H. Liao, H. Wang, X. Rong, E. Li, R.-H. Xu, and Y. Peng, "Mesenchymal stem cells attenuate radiation-induced brain injury by inhibiting microglia pyroptosis," BioMed Research International, vol. 2017, Article ID 1948985, 11 pages, 2017. 


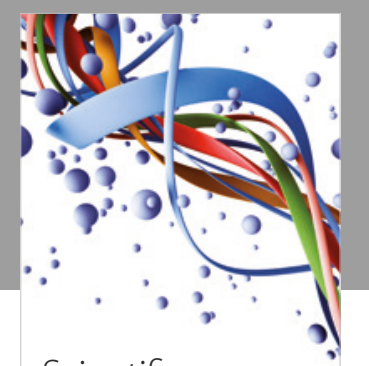

Scientifica
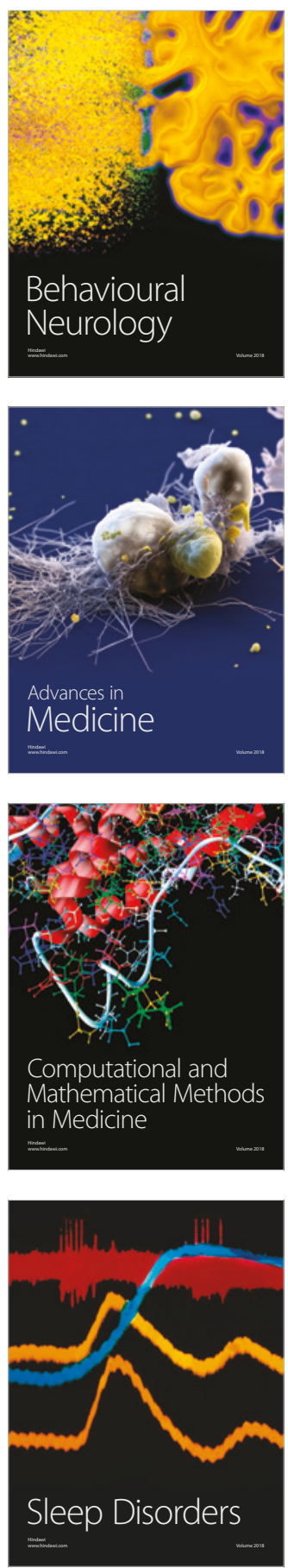

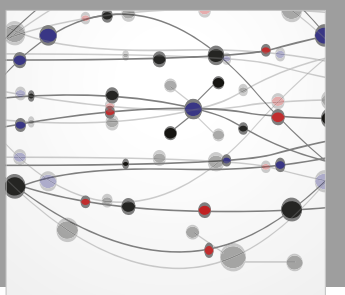

The Scientific World Journal

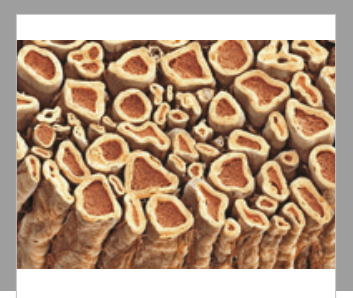

Case Reports in

Neurological Medicine

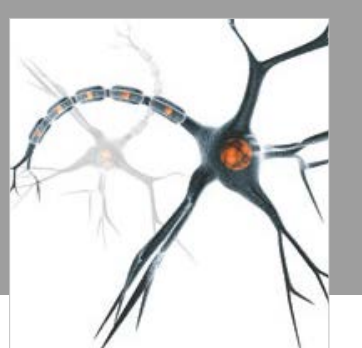

Neural Plasticity

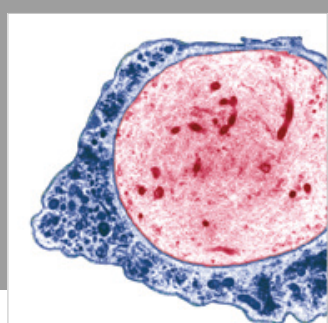

Multiple Sclerosis

International

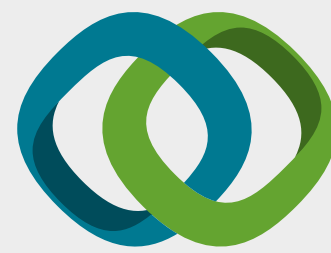

Hindawi

Submit your manuscripts at

www.hindawi.com
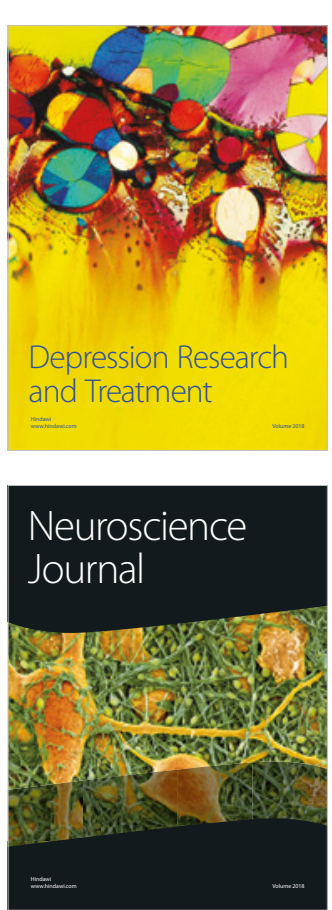

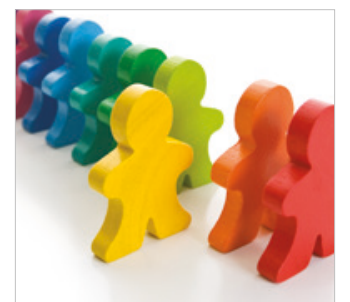

Autism

Research and Treatment
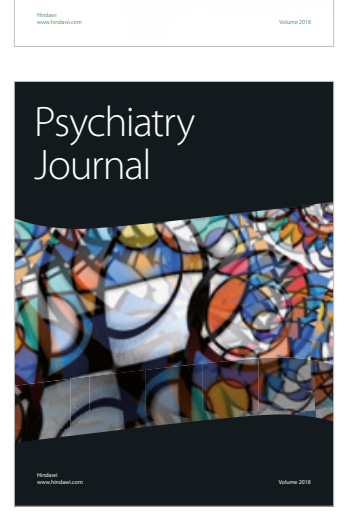
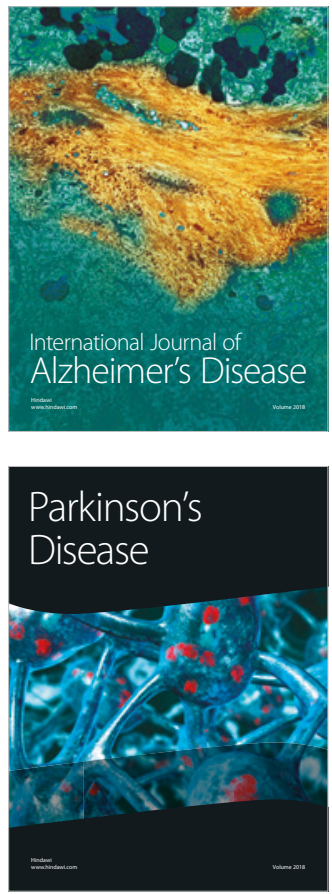
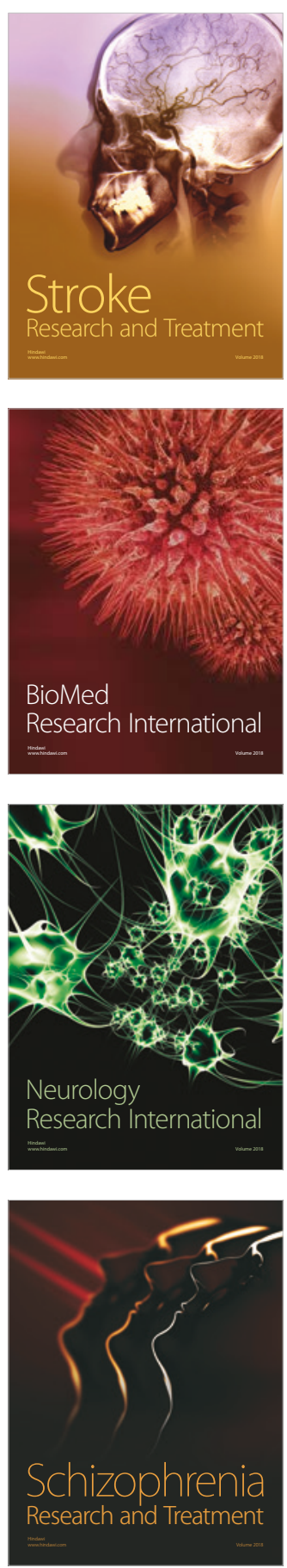